\title{
Monitored Laser Grinding Using Real Time Nanobots Data: A Novel Mudcake Removal Approach
}

\section{Dhruvin Kaneria* and Tirth Raval}

School of Petroleum Technology, Pandit Deendayal Petroleum University, India

\begin{abstract}
For ensuring casing and cementing quality, mud cake removal is essential. Various problems like stuck pipe take place because of the presence of mud cake. Mechanical methods of water jetting and chemical methods by means of acids, oxidizers, chelating agents, etc., are currently employed for mud cake removal. However, water jetting can cause water blockage problems and has detrimental effects on well productivity. Also, mud cakes of different permeability will not be removed by same intensity water jets. Acids and oxidizers are very reactive but nonspecific species, imposing several post perforation problems and formation damage. As an alternative, we propose a new method in this study with the usage of nanobots and laser grinding. The nanobots, placed in carrier, can be deployed in all directions into the targeted zone. These non-adherent and self-propelled nanobots will move through the vertical permeability of the mud filtrate and would interpret the petro physical properties of the mud filtrate. The sensors would then send this data to molecular processor and with the help of radio frequency transmitter and receiver, we could immediately interpret the real time data from every point in the zone of interest. This data would be used to change the intensity of the lasers in accordance with the petro physical properties. Lasers, lowered through wireline, would then vaporise the mud cake through spallation according to its thickness and will grind the mud cake by creating popped holes. This novel idea of real time laser grinding with the help of nanobots holds great potential in removing mud cake precisely and efficiently and could also be useful in multilateral and horizontal wells.
\end{abstract}

Keywords: Mudcake; Laser grinding; Nanobots

\section{Introduction}

Mud cake is the solid particles deposited on the pores of the formation creating a form of barrier when the drilling fluid is forced against the formation under an applied pressure [1]. The mud cake formed along the open hole formation may cause differential pipe sticking and increases torque and drag forces of the drill pipe [2]. This causes drilling operator to stop drilling and perform frequent tripping or over pull to release the stuck pipe. This event may lead to NonProductive Time (NPT) and increases the operational cost.

A mud cake formed is not like metals, but they contain interconnected pores in it. This permeability of the mud cake changes with many factors such as the lithology on which it is being formed, the rate of penetration, the annular velocity, hole diameter, the rate of discharge of the pump and also on the amount of time given to the mud to be present inside the wellbore. To improve the cementing quality and to decrease the amount of drilling fluid adhering to the wellbore, the removal of the mud cake is of utmost importance [3].

The working and success of current methods for cleaning is variable depending on the condition of the well to be treated. Water jetting method used to remove the mud cake has adverse effect on the well performance and the well productivity through sanding and water blockage [4]. As the water used to remove the mud cake is not retrieved completely from the wellbore it may remain in the formation. Also the mudcake's changing permeability would play a major role as the same intensity jetting would not be effective for unevenly deposited mudcake. Also the mud cake will not be removed efficiently from every part of the wellbore due to water-jetting's typical helical flow. The method of using chemical means like acids, oxidizers, chelating agents, enzymes have also been used but they have their own problems. Acids and oxidizers are very reactive but non-specific species. High amounts of acids and oxidizers would be needed while treating horizontal and multilateral wells where considerable amount of section needs to be removed. Enzymes and chelating agent are also not helpful in heterogeneous formations [5].

\section{Materials and Methods}

\section{Proposed solution}

A novel approach can be leveraging the promise of nanotechnology as well as monitored laser grinding. The permeability of the mud cake formed, petro physical properties, thickness and the other useful data about the zone of interest can be obtained by nanosensors. This can be done with the deployment of the nanorobots or nanobots into the mudcake formation to get all the relevant data of the mudcake. A laser system, conveyed through wireline will then use this data to control the intensity and thus remove mudcake with utmost precision. Laser system provides superior precision, direction control and the fact that its intensity can be varied could be extremely useful for various downhole applications. Further discussion in the paper is on the working and design of nanobots and how laser system would be applicable.

\section{Deploying nanobots: Its working and design}

The pores and the pathways found inside the mudcake formation could also be as low as $1000 \mathrm{~nm}$ and so the nanobots of specific dimension less than it can be used. A nanoscale robot with dimension of $500 \mathrm{~nm}$ could move through the pores of the mudcake and provide useful data. The term robot only means a mechanical device that is capable of performing one or more task like manufacturing, transportation etc. on command or programmed in advance [6]. These nanobots are

"Corresponding author: Dhruvin Kaneria, School of Petroleum Technology, Pandit Deendayal Petroleum University, India, Tel: +91-7874389261; E-mail: dhruvin.kaneria.india@gmail.com

Received November 29, 2017; Accepted December 19, 2017; Published December 26, 2017

Citation: Kaneria D, Raval T (2017) Monitored Laser Grinding Using Real Time Nanobots Data: A Novel Mudcake Removal Approach. J Pet Environ Biotechnol 8 352. doi: $10.4172 / 2157-7463.1000352$

Copyright: $\odot 2017$ Kaneria D, et al. This is an open-access article distributed under the terms of the Creative Commons Attribution License, which permits unrestricted use, distribution, and reproduction in any medium, provided the original author and source are credited. 
sent into the mudcake or the zone of interest by a carrier sent into the wellbore. The carrier will have dimensions of 1.5 " to 1.75 " of diameter. These nanobots are then sent into the mudcake by shooting them into the desired zone. At a time 100's and 1000's of nanobots can be deployed to get the petro physical data. If any of the nanobot is not deployed in the correct zone of interest or has moved towards the flushed zone with deployment, it can be programmed and managed using the onboard computer of nanobot or the controller and the processor present inside the carrier [7]. The nanobot can communicate with the control computer by sending and receiving data through fixed receivers and transmitters located in the wellbore. The nanobot will use sensors to identify the amount of mud filtrate, the pore throat width, and other petro physical properties. The on-board computer present in the carrier system or the wellbore can control the actions of the nanobots [8]. The position and the velocity can be managed by this controller.

These nanobots would be made from adherent resistant material so they can move inside the cake easily. The shape could be spherical to oval by which the resistance can be reduced. A nanobot can also be in a shape of a fish or a capsule. The adherence resistance design could prevent and reduce the viscous substances in the mudcake to adhere to the nanobot body. The body could be made of fused carbon nanotubes(CNTs) which can give strength and provide protection to nanobots and its inside components. Also the materials like carbon nanotubes can withstand high temperatures which can be used in high temperature high pressure zones [9].

The nanobots deployed in the mudcake will transmit the data obtained using the radio frequency to the receiver present on the laser system device. There can be different types of sensors inside the nanobots. The positional sensors would indicate its position and velocity so that they can be programmed or changed. There could be fluid properties sensors that would not only indicate the fluid properties of the invasion by the drilling fluid but also give data of temperature and pressure. The fluid data including the filtrate's saturation in its pathway can give useful information about the permeability of mudcake [10]. The viscosity of the fluid can be measured by measuring the velocity of the nanobot (through the positional sensors) and comparing it with the propulsion power applied. Some sensors would also measure the physical dimensions such as the pore throat aperture. The pore width could also be measured by recording the position of the nanobot as it moves across the diameter of pores in the mudcake. The positional data of the nanobot thus is analysed to determine the physical dimensions of the pore and the permeability.

The nanobots require power to perform task and to move across the vertical permeability of the mudcake [11]. Various propulsion devices can be used to propel these nanobots throughout its travel. These propulsion devices let the nanobots overcome the viscous and gravitational forces. The simplest propulsion device could be the filtrate itself, but for maintaining the motion a powered propulsion device should be used as we need to move against the gravity. The propeller could be a molecular propeller containing blades and shafts. Figure 1 shows the nanobot with the propulsion device and sensor arrangement. This could also be made from fused materials like carbon nanotubes. The methods of installing vibrating membranes could also provide a thrust to propel the nanobots. These can be alternatively tightened and relaxed to produce thrust. Also the structure could be made like that of insects by which these can crawl, by providing mechanical legs or installing fins.

When the sensor detects the changing amount of mud filtrate in the mudcake the transmitter would transmit the data to the receiver and thus the real-time data can be obtained as the nanobot moves. The radio frequency transmitter transmits, and fixed receiver on carrier receives. The data obtained by the nanobots not only include the permeability information of the mudcake but also important data regarding the changing thickness of the mudcake and the distance of it from the laser system. Thus, laser parameters would be adjusted as per the data received. Figure 2 shows the receiver and transmitter arrangement in the wellbore. This information will be extremely important for other operations as well like cementing and casing.

The wellbore is divided into parts or sections (quadrants) and the nanobots deployed in a particular part would provide the data pertaining to that part only. By this, commingling of different data obtained by numerous nanobots to the receiver wouldn't occur. If we divide the wellbore into 4 quadrants and place a receiver for each, then data of that quadrant would instruct the laser system accordingly to vary its intensity (Figure 3 ).

It should be noted that different lithology can be encountered like shale, sandstone, coal, anthracite etc. in the wellbore and also may not have mud filtrate invasion and no presence of mudcake. Figure 4 shows such changing lithology. By mechanical methods of water jetting the water may even be jetted to such lithology and could be wasted. The laser grinding would be stopped when such impermeable layers come and would again commence when needed. The on-board computers may also store the mud filtrates invasion potential information for each of lithology for future prediction of the mudcake formation and its thickness when the drilling fluid is again circulated into the wellbore.

In case of horizontal wells, the laser system can again be sent horizontally, but this time the nanobots would be moving along the horizontal permeability of the formation. The same approach can be adopted for multilateral wells. A carrier with the laser, receiver,

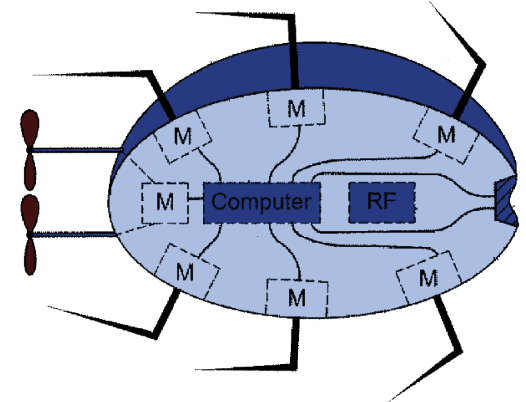

Figure 1: Nanobot with the propulsion device and sensor arrangement.

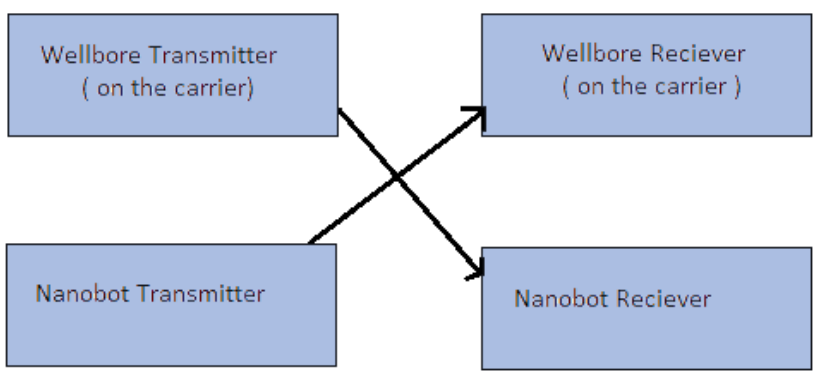

Figure 2: Receiver and transmitter arrangement in the well-bore 


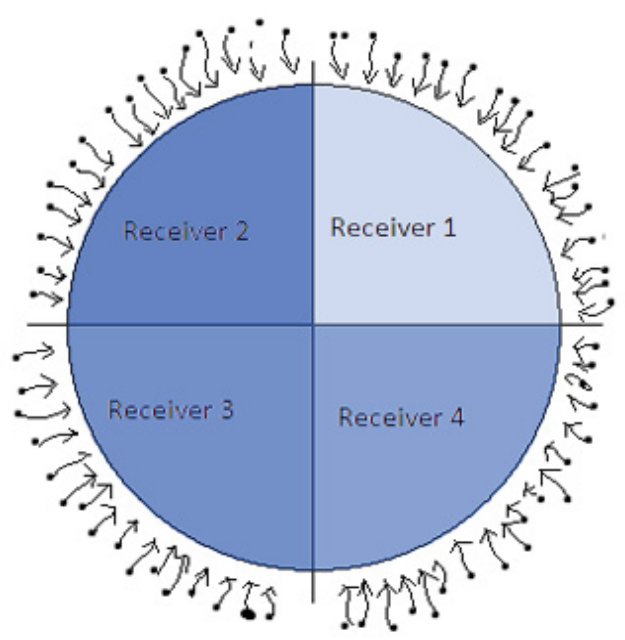

Figure 3: Quadrant showing the laser system accordingly to vary its intensity.

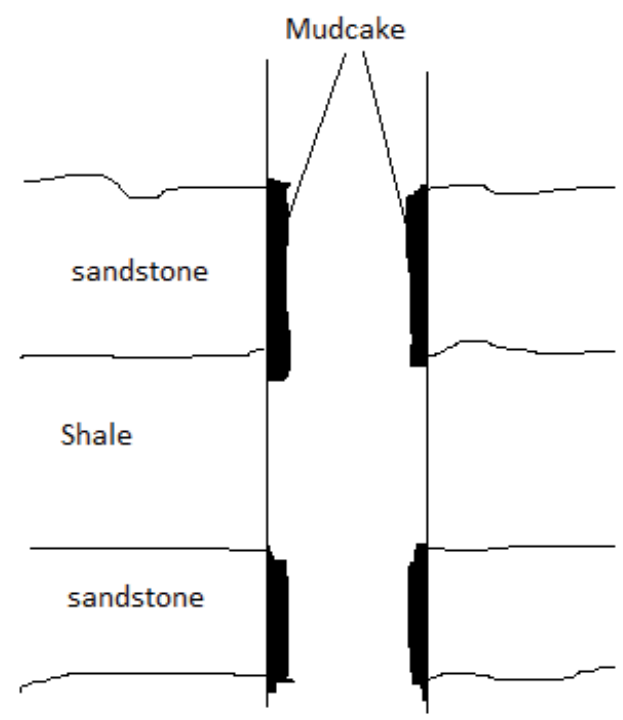

Figure 4: Changing lithology.

processor and nanobots assembly could be sent within each branch of the multilateral well. All of the deployed nanobots in each branch could be operated and worked simultaneously and much time could be saved.

\section{Laser system and mechanism and design}

Laser drilling of rocks is based on face-heating phenomenon. The process of laser spallation utilizes the laser induced thermal stress to fracture and eventually grind the mudcake into small fragments. The laser radiated on the filter cake is reflected, dispersed or absorbed among which the absorbed radiations treats it. When the illuminated spot on the surface of the mudcake reaches its boiling temperature, material removal would start due to the process of vaporisation and melt expulsion. High laser energy with low thermal conductivity would cause the temperaure to increase instantaneously and concentrate locally on the surface of the mudcake. And the effectiveness of this expulsion of the filter cake would be proportional to the laser power, wavelength and focal length [12] (Figures 5 and 6).

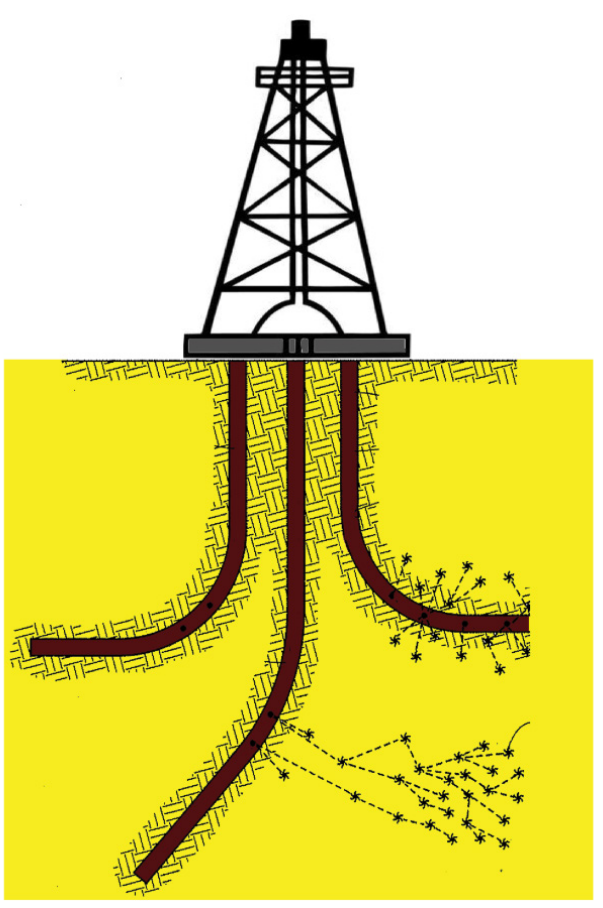

Figure 5: Laser system and mechanism and design.

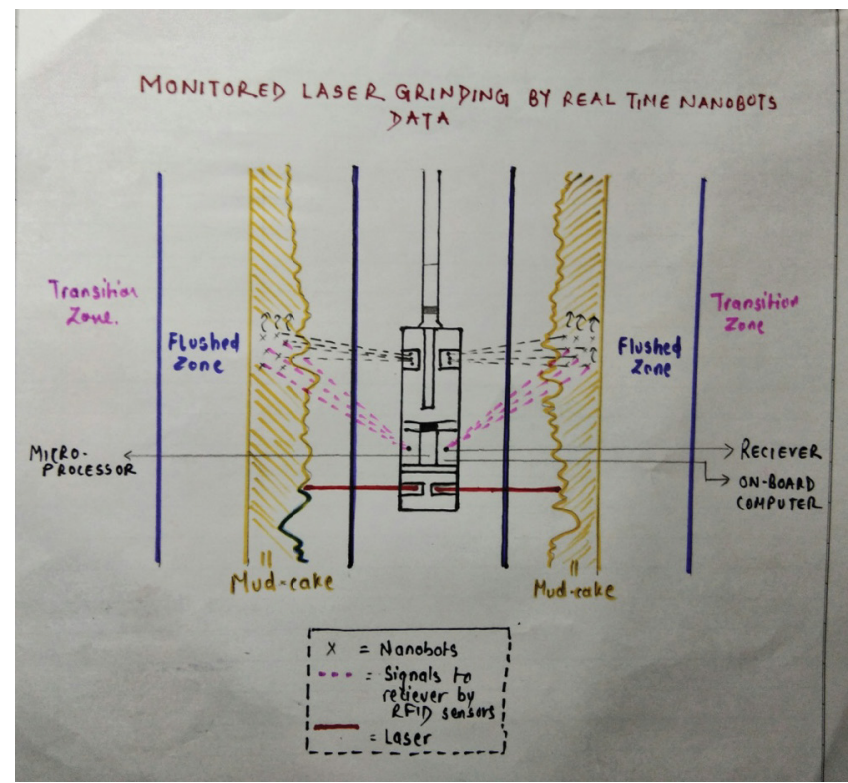

Figure 6: The complete mechanism of the laser system device sent inside the wellbore for mud-cake removal.

The carrier would be consisting three main components pertaining to laser grinding. The three units namely generator, cooling system and laser system can be stacked vertically in the carrier [13]. The beam intensity would play a major role in the cleaning of filter cake i.e., lasing with a focussed or divereged beam. A cylindrical hole(parellel) would be obtained by using a collimated source where the beam diameter would remain relatively constant at any distance from the optics to the mudcake. A converging or diverging lens placed could help in cleaning 
a smaller or greater portion with respect to optics respectively which can have a significant impact on the time taken. Lenses would play major role in placing the mudcake to removed at the converging side of the focal point as it would take less amount of specific energy the amount of energy required to remove a unit volume of material). The nanobots aqquired data for a particular cross-section and its volume would alter the laser power and eventually the specific energy [14].

Based on mudcake thickness and permeablity we have evaluated the time it would require to remove the mudcake from that particular formation. We have estimated the time required to remove the mudcake of different thickness from the mathematical correlations and have found that the time required by the laser technology is much less than the conventional technology that are being used currently in oil and gas industry. The mathematical calculations are shown in detail in the Tables 1 and 2. Based on various research carried out on laser grinding that have been conducted on different kind of rock sample it could be concluded that if we have different kind of continous phase like oil water or brine in the sample then the specific energy required to grind it using laser would be different. The puring gas used for the laser also plays vital role in grinding process. The selection of purging gas depends on its availability and economical constrains associated in the project. The optimized table that could be evaluated which gives the relationship between the specific energy, purging gas and continuous phase present in the mud cake is shown in Tables 1 and 2 (Graphs 1 and 2).

\section{Additional advantages of laser system for Borehole applications}

Economics is an essential consideration for implementation of any technology. This laser system would not just be used during mudcake removal but can also be used during other phases of well development. In well completion, perforation channels must be made through the casing wall and cement and into the rock formation to allow formation fluids to enter the well. Unlike the conventional explosive charge perforation that often causes reduction of rock permeability, laser perforation would enhance the rock permeability, thus increasing the oil or gas production rate of the well.

Several tests show that $\mathrm{CO}_{2}$ laser can perforate the rock as efficiently as the other types of high power lasers and the permeability of the rock lased by pulsed $\mathrm{CO}_{2}$ laser beam increases up to $566 \%$ compared to nonlased rocks due to clay dehydration and micro fractures induced by the high temperature gradient and phase transformation volume expansion generated in the rock while lasing [15].

Also, laser cleaning has long been used and the same phenomenon can be used to control any corrosion or unwanted depositions in the wellbore. Laser rock spallation action induces thermal stress to fracture and cause a break through the rock by creating micro fragments before melting of the rock. Thus micro fractures are induced and along-with removal of mudcake, it also enhances petrophysical properties [16].

\begin{tabular}{|c|c|c|c|}
\hline \multirow{2}{*}{ Types of purging gas } & \multicolumn{2}{|c|}{ Specific Energy (kJ/cc) } \\
\cline { 2 - 4 } & Water based mud & Brine water based mud \\
\hline Ar & 1.71 & 1.52 \\
\hline Air & 1.9 & 1.71 & 2.28 \\
\hline $\mathrm{N}_{2}$ & 1.615 & 1.805 & 2.47 \\
\hline Helium & 2.28 & 2.375 \\
\hline
\end{tabular}

Table 1: Comparison of specific energies of various methods.

\begin{tabular}{|c|c|c|c|c|c|c|c|c|}
\hline $\begin{array}{l}\text { Experiment } \\
\text { number }\end{array}$ & $\begin{array}{l}\text { Laser power } \\
(\mathrm{Kw})\end{array}$ & $\begin{array}{l}\text { Thickness of } \\
\text { the mud cake } \\
\text { (cm) }\end{array}$ & $\begin{array}{l}\text { Diameter of bore } \\
\text { without mud } \\
\text { cake }(\mathrm{cm})\end{array}$ & $\begin{array}{c}\text { Effective } \\
\text { diameter of the } \\
\text { borehole }(\mathrm{cm})\end{array}$ & $\begin{array}{l}\text { Height of } \\
\text { the mud } \\
\text { cake }(\mathrm{cm})\end{array}$ & $\begin{array}{l}\text { Volume to be } \\
\text { removed by laser } \\
\text { action (cc) }\end{array}$ & $\begin{array}{l}\text { Energy required } \\
\text { for removal mud } \\
\text { cake }(k J / c c)\end{array}$ & $\begin{array}{l}\text { Time required for } \\
\text { the removal of mud } \\
\text { cake }(\mathrm{sec})\end{array}$ \\
\hline 1 & 5.34 & 0.2 & 25.4 & 25.2 & 10 & 318.0571429 & 1.61 & 1.598227216 \\
\hline 2 & 5.34 & 0.4 & 25.4 & 25 & 10 & 633.6 & 1.61 & 3.183820225 \\
\hline 3 & 5.34 & 0.6 & 25.4 & 24.8 & 10 & 946.6285714 & 1.61 & 4.756779026 \\
\hline 4 & 5.34 & 0.8 & 25.4 & 24.6 & 10 & 1257.142857 & 1.61 & 6.31710362 \\
\hline 5 & 5.34 & 1 & 25.4 & 24.4 & 10 & 1565.142857 & 1.61 & 7.864794007 \\
\hline 6 & 5.34 & 1.2 & 25.4 & 24.2 & 10 & 1870.628571 & 1.61 & 9.399850187 \\
\hline 7 & 5.34 & 1.4 & 25.4 & 24 & 10 & 2173.6 & 1.61 & 10.92227216 \\
\hline 8 & 5.34 & 1.6 & 25.4 & 23.8 & 10 & 2474.057143 & 1.61 & 12.43205993 \\
\hline 9 & 5.34 & 1.8 & 25.4 & 23.6 & 10 & 2772 & 1.61 & 13.92921348 \\
\hline 10 & 5.34 & 2 & 25.4 & 23.4 & 10 & 3067.428571 & 1.61 & 15.41373283 \\
\hline 11 & 5.34 & 2.2 & 25.4 & 23.2 & 10 & 3360.342857 & 1.61 & 16.88561798 \\
\hline 12 & 5.34 & 2.4 & 25.4 & 23 & 10 & 3650.742857 & 1.61 & 18.34486891 \\
\hline 13 & 5.34 & 2.6 & 25.4 & 22.8 & 10 & 3938.628571 & 1.61 & 19.79148564 \\
\hline 14 & 5.34 & 2.8 & 25.4 & 22.6 & 10 & 4224 & 1.61 & 21.22546816 \\
\hline 15 & 5.34 & 3 & 25.4 & 22.4 & 10 & 4506.857143 & 1.61 & 22.64681648 \\
\hline 16 & 5.34 & 3.2 & 25.4 & 22.2 & 10 & 4787.2 & 1.61 & 24.05553059 \\
\hline 17 & 5.34 & 3.4 & 25.4 & 22 & 10 & 5065.028571 & 1.61 & 25.45161049 \\
\hline 18 & 5.34 & 3.6 & 25.4 & 21.8 & 10 & 5340.342857 & 1.61 & 26.83505618 \\
\hline 19 & 5.34 & 3.8 & 25.4 & 21.6 & 10 & 5613.142857 & 1.61 & 28.20586767 \\
\hline 20 & 5.34 & 4 & 25.4 & 21.4 & 10 & 5883.428571 & 1.61 & 29.56404494 \\
\hline
\end{tabular}

Table 2: Evaluation of the time required for the removal of bore hole mud cake having different thickness. 


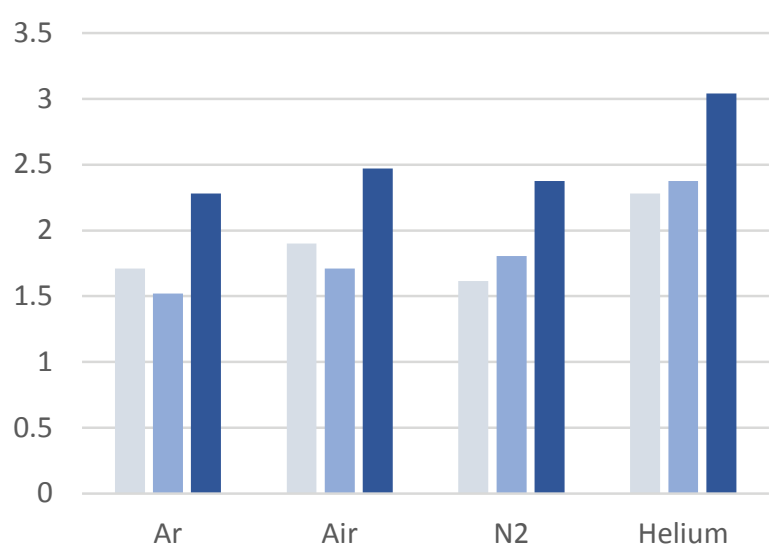

\section{Specific Energy (kJ/cc) Water based mud Specific Energy (kJ/cc) Brine water based mud - Specific Energy (kJ/cc) Oil based mud}

Graph 1: Comparison of specific energy required for different types of purging gas

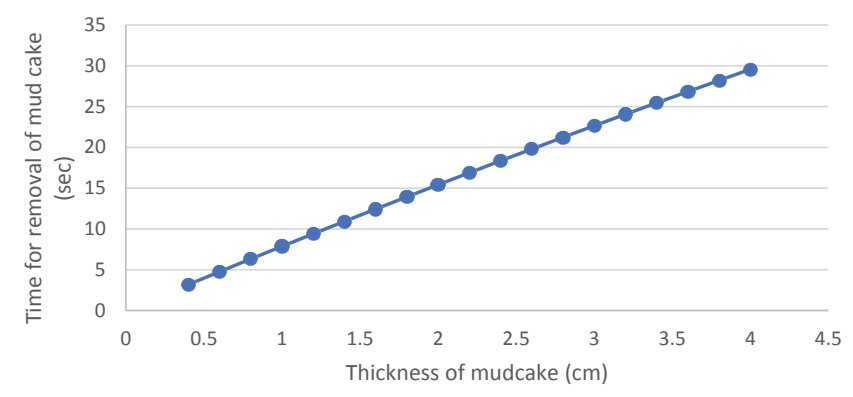

Graph 2: Time required for the removal of mud cake (sec) vs thickness of mud cake $(\mathrm{cm})$.

\section{Conclusion}

The precision and control laser system provide could significantly find applications in various downhole applications. Laser-rock interaction tests have proven that lasers can penetrate all rock types including granite, much faster than conventional methods. Laser can also induce fractures in the rocks by thermal expansion. The application of high power lasers can also enhance petrophysical properties such as permeability and porosity. Laser systems can be used for the mudcake removal more efficiently than the conventional mechanical and the chemical methods and thus finds applications in horizontal as well as multilateral wells. With the help of laser technology, the perforation can be done at desired depths and at desired rates. Such a device would also be economical as it could be used during various stages of well development, from mud cake removal to perforations, from corrosion removal and wellbore cleaning to enhancing petrophysical properties and wellbore stimulation. The efficiency of laser cleaning depends on the power of laser, the wavelength and the focal length and thus the realtime data acquired by the nanobots would empower the laser system to adjust these parameters for effectiveness. Thus, the process of mudcake removal using nanobots data has the potential to find application in industry. This novel approach provides superior accuracy and direction control at reasonable economics.

\section{References}

1. Mudcake (2000) Drilling fluids, formation evaluation.

2. Bourgoyne AT, Millheim KK, Chenevert ME (1986) Applied drilling engineering Textbook Series, SPE, Richardson, Texas, USA.

3. Zhang J, Wang J, Meng Q, Li X, Zhu B (2015) Mud cake removing to improving the well cementing quality. In: $5^{\text {th }}$ International Conference on Advanced Engineering Materials and Technology, Osaka, Japan.

4. Zain ZM, Sharma MM (2001) Mechanisms of mud-cake removal during flowback. Society of Petroleum Engineers, Washington, D.C., USA.

5. Nasr-El-Din HA, Al-Otaibi MB, Al-Qahtani AA, Samuel MM (2007) An effective fluid formulation to remove drilling fluid mud cake in horizontal and multi-lateral wells. Society of Petroleum Engineers.

6. Isaac A (1996) The robot chronicles. Gold. Voyager, London. pp. 224-225.

7. Goodwin S (2014) U.S. Patent No. WO2014022705 A1. Patent and Trademark Office, Washington D.C., USA.

8. Smith FM (2017) U.S. Patent No. US9566711 B2. Patent and Trademark Office, Washington, D.C., USA.

9. Dong L, Subramanian A, Nelson BJ (2007) Carbon nanotubes for nanorobotics. Nanotoday 2: 12-21.

10. Freese RP, Jones CM, Pelletier MT, Daussin RD, Loveless DM, et al (2016) U.S. Patent No. US9441149 B2. Patent and Trademark Office, Washington, D.C., USA.

11. Kamal RA, Sanni ML, Kanj MY (2010) U.S. Patent No. US20100268470 A1. Washington, DC: U.S. Patent and Trademark Office, Washington, D.C., USA.

12. Gahan BC, Parker RA, Batarseh S, Figueroa H, Reed CB, et al. (2001) Laser drilling: Determination of energy required to remove rock. Society of Petroleum Engineers, Washington, D.C., USA.

13. Mahdi B, Montazeri GH, Hafizi R (2014) Theoretical studies of laser cleaning mechanism for wellbore mud cake removal. $6^{\text {th }}$ Saint Petersburg International Conference and Exhibition on Geosciences 2014: Investing in the Future.

14. Gahan C, Brian D, Samih B (2005) Laser drilling - Drilling with the power of light.

15. Bakhtbidar M, Ghorbankhani M, Alimohammadi M, Kazemi Esfeh MR, Rezae P (2011) Application of Laser technology for oil and gas wells perforation. Society of Petroleum Engineers, Washington, D.C., USA.

16. Graves RM, Bailo ET (2005) Analysis of thermally altered rock properties using high-power laser technology. Petroleum Society of Canada, Washington, D.C., USA. 